\title{
Stoneflies (Plecoptera: Perlidae) of Nicaragua
}

\author{
STEFANO FENOGLIO \\ University of Piemonte Orientale Di.S.A.V., Via Bellini 25, I-15100 Alessandria, Italy \\ e-mail:fenoglio@unipmn.it
}

\begin{abstract}
Neotropical Plecoptera represent an interesting subject of study, for their phylogenetic, biogeographical and ecological importance. The Plecopterofauna of a large portion of the Neotropics is represented by only one genus of Perlidae, Anacroneuria Klapálek. This work provides information about the stonefly fauna of Nicaragua, a country for which few previous investigations have been undertaken for this insect group. Eight species of Anacroneuria are currently recorded, including A. curiosa Stark, A. holzenthali Stark, A. planicollis Klapálek, A. starki Fenoglio \& Morisi, A. talamanca Stark, A. litura (Pictet), and the two new records: $A$. divisa (Navas), and $A$. lineata (Navas). In addition, a key for adult males is provided and the putative nymph of $A$. talamanca is described.
\end{abstract}

KEY WORDS.-Plecoptera, Perlidae, Anacroneuria, Neotropics, Nicaragua.

\section{INTRODUCTION}

The Plecopterofauna of a large portion of the Neotropics is represented by only one genus of Perlidae, Anacroneuria (Klapálek). This genus is the dominant element in the stonefly fauna of a great part of Central and South America (Jewett 1958). Following a period of sporadic studies and observations, recent works underlined its diversity and richness (Froehlich 1981; Stark 1995, 1998, 1994; Stark et al. 1999). Biogeographically, a northern origin was initially assumed for this group (Illies 1965). However, on the basis of the great taxonomic diversity of the Anacroneuria, its immigration from North America during the Miocene appears to be a too modern phenomenon. Thus, Stark and Gaufin (1976) and Zwick (2000) suggested that the dispersal of Anacroneurinii may have occurred from Asia or from Europe through Africa to South America during the Cretaceous.

Neotropical stoneflies of the genus Anacroneuria represent an interesting subject for systematic, biogeographical, phylogenetic, and ecological studies. One of the most interesting aspects is the peculiar distribution of the Anacroneuria. Indeed, while

ms. received Feb. 17, 2006; accepted Aug. 28 , 2006.
Central America comprises one of the most biologically diverse and rich regions of the world (Marshall and Liebherr 2000), only one genus of Plecoptera has been able to colonise this area. To explain the scarcity of stoneflies in these environments, we hypothesize the existence of some determinant limiting factors that have only been overcome by particularly adapted groups. Recently, Fenoglio and Rosciscewska (2003) suggested that egg structure could represent the key-factor underlying this adaptation: thinner eggshell layers and the specific features of Anacroneuria eggs may be considered as an adaptation of these stoneflies to the specific conditions of neotropical waters (high temperatures and relatively low dissolved oxygen) and, possibly, a factor that facilitated the colonization of these environments.

Until recently, virtually nothing was known about the ecology of this large group (Stewart and Stark 1993). Fenoglio and Tierno de Figueroa (2003), on the basis of gut contents analysis, suggested that adults don't ingest solid food and are probably short-lived. Because non-feeding species tend to emerge with fully formed eggs, this taxon seems to base its energetic demand for adult life and oogenesis on the pre-imaginal diet. In a recent study, the gut contents of Anacroneuria nymphs from Guatemala, Honduras, and Nicaragua 
were examined (Fenoglio 2003). The results suggest a change in food preference between different instars, with smaller stages being detritivores and larger ones being carnivores feeding on a broad range of aquatic insects. This is in agreement with what is usually reported for Perloidea nymphs (Hynes, 1976).

In this work I report information about the occurrence and distribution of stoneflies in Nicaragua.

\section{MATERIALS AND METHODS}

Information in this work is derived from two sources: 1) field expeditions of S. Fenoglio and J.M. Maes, and 2) bibliographic investigations and previous studies of $S$. Fenoglio and B. Stark. All adult specimens were captured with light traps. External anatomical details, such as pronotum and head sculpture, and male hammer and female subgenital plate characteristics have been examined. In some cases, the aedeagus has been extracted after detaching the abdomen and placing it in a solution of $\mathrm{KOH}$ brought to a boil. Examined specimens were deposited in the following collections: USNM (United States National Museum, Washington D.C.), MCCI (Natural History Museum of Carmagnola, Italy), and MELN (Museo Entomologico de León, Nicaragua).

\section{RESULTS}

In a pioneering study related to the stonefly fauna of Nicaragua, Maes (1988) reported Anacroneuria flavominuta Jewett, $A$. nigrocinta Pictet and another undescribed species. However, further investigations into the taxonomic and biogeographic knowledge of the group led to the conclusion that this finding was probably incorrect. Indeed, these species are actually known only from Mexico (Stark, 1998 and Stark and Kondratieff, 2004). Stark (1998) reported Anacroneuria curiosa Stark, A. holzenthali Stark, and A. planicollis Klapálek from Nicaragua. More recently (i.e., 19982001), field expeditions and visits to the U.PO.NIC. and the Entomological Museum of León resulted in the collection of specimens from different points of the Rio San Juan Basin (S-W Nicaragua). Only A. talamanca was found there (Fenoglio and Morisi 2001b). More recently, Fenoglio and Morisi (2001a) also described a new species, A. starki, from Cerro Saslaya. In this study, two species, $A$. divisa and $A$. lineate, both derived from the field collection of J.M. Maes, were described and represented first official record for their occurrence in the Nicaraguan fauna.

Because nymphs and adult females of many Plecoptera species are not described, the species taxonomic key presented here is limited to use with adult males.

Provisional key to know Nicaraguan male Anacroneuria

1. Median pronotal band yellow (Fig. 1) --------- 2

- Median pronotal band brown (Fig. 2) -.----.---- 6

2. Hammer poorly developed (Fig. 3) ---------- starki

- Hammer well developed and thimble like (Fig. 4) --.--------- 3

3. Head without brown pigment area between and behind the ocelli -.-.-

- Head with brown pigment area in ocellar area

4. Aedeagal apex trilobate, massive with large wing-like shoulders. ----

- Aedeagal apex not as above -.-.-.--- 5

5. Lateral aspect of aedeagal apex longer than wide; wing membrane transparent.

Lateral aspect of aedeagal apex wider than long. Wing membrane brownish. litura

6. Aedeagal apex with three subequal lobes planicollis

- Aedeagal apex simple ----.----------- 7

7. Lateral aspect of aedeagal apex longer than wide (Fig. 5) lineata

Lateral aspect of aedeagal apex wider than long (Fig. 6) divisa 


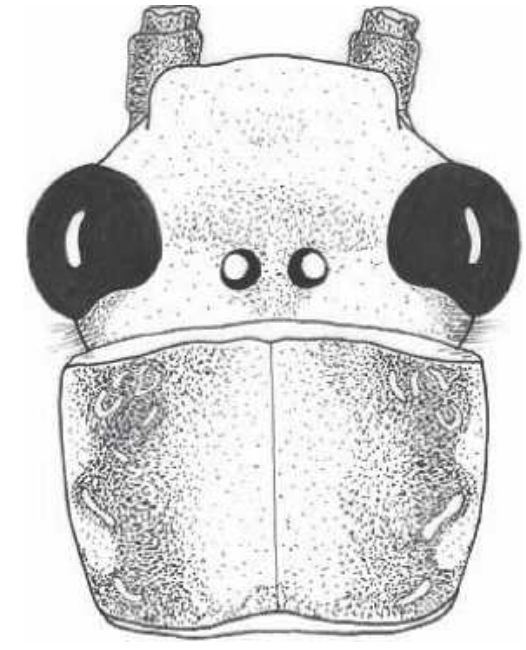

FIG. 1. Head and pronotum of A. starki, with median pronotal stripe yellow.

\section{Anacroneuria starki Fenoglio \& Morisi} 2001

Fenoglio and Morisi 2001.

Adult habitus: Head yellow with pale brown trapezoidal pattern in the area between eyes and ocelli. Median pronotal stripe yellow, conspicuous midlateral stripes brown with irregular external edge and pale margins. Wing membrane brown, veins brown.

Male and female description: see Fenoglio and Morisi 2001a.

Nymph: unknown

Material: Cerro Saslaya, Zelaya, altitude 700 meters, IV 1996, J.M. Maes (MCCI; MELN)

\section{Anacroneuria holzenthali Stark 1998}

Stark 1988.

Adult habitus: Dark head pattern covers ocelli and extends forward to midpoint of lappets; pattern interrupted by a pair of minute pore sized unpigmented spots and a large mesal spot. Pronotum dark except for slender mesal stripe and anterolateral margin spots. Wing membrane brown, veins brown.

Male and female description: see Stark 1988.

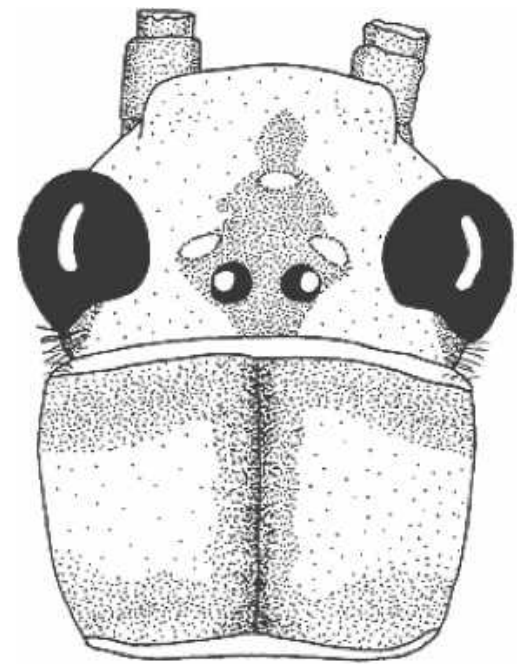

FIG. 2. Head and pronotum of $A$. lineata, with median pronotal stripe brown.

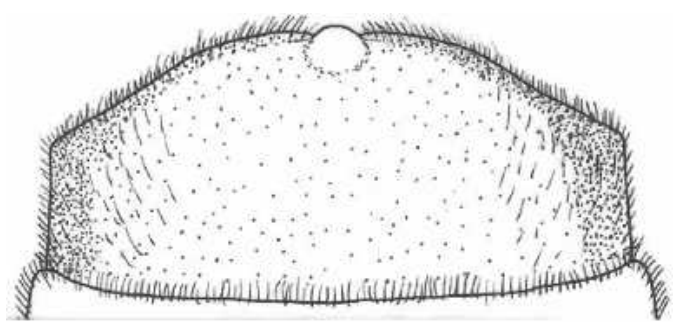

FIG. 3. Hammer a low rounded mound.

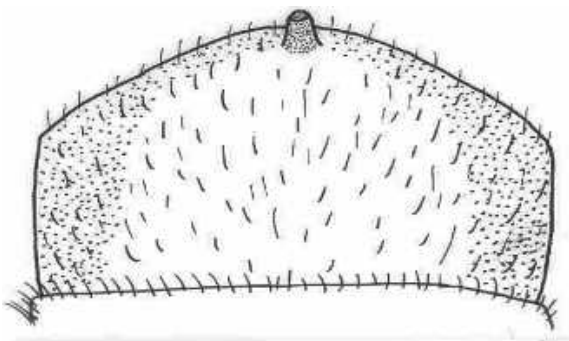

FIG. 4. Hammer thimble shaped.

Nymph: unknown

Material: Chontales, Santo Domingo, XI 1985. J.M. Maes (USNM).

\section{Anacroneuria talamanca Stark 1998}

Stark 1988.

Adult habitus: Ocellar area covered by a small brown quadrangle; lateral margins 


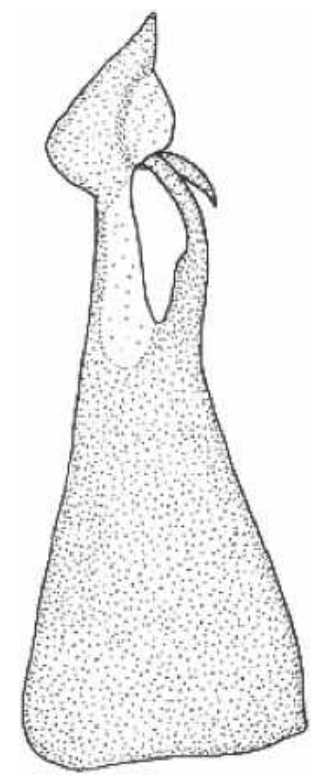

FIG. 5. Lateral view of $A$. lineata aedeagus.

of frons diffuse brown, lappets brown. Median pronotal stripe yellow, lateral stripes brown. Wing membrane transparent, veins brown.

Male and female description: see Stark 1988, Fenoglio and Morisi 2001b.

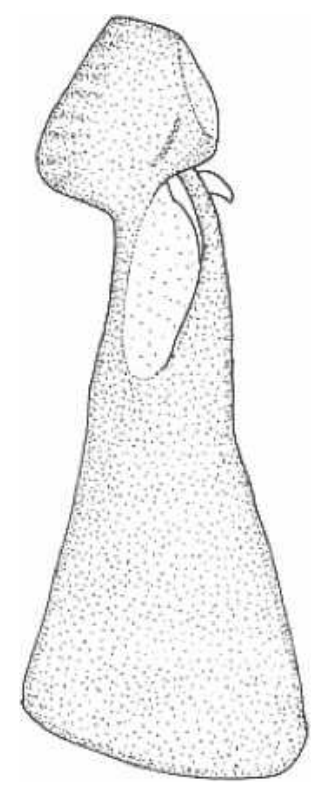

FIG. 6. Lateral view of $A$. divisa aedeagus.
Nymph - Body length 9-13 mm. Head brown forward a line between ocelli and eye anterior margin and between ocelli. Pale incomplete $\mathrm{M}$ line. Pronotum pattern brown, with pale sculptures (Fig. 7). Anterodorsal femoral bristles distributed mainly in the marginal areas, with long tiny bristles accompanied with short spines (Fig. 8). Nymphs of this species were found in the Bartola river ( $30 \mathrm{~m}$ asl), a lowland forested tributary of Rio San Juan.

Material: Boca de Sabalo, Bartola, 21 X 1999, S. Fenoglio; Boca de Sabalo, Bartola, 13 III 2001, M. Meyer (MCCI).

Anacroneuria curiosa Stark 1998

Anacroneuria flavominuta: Harper 1992.

Adult habitus: Head yellow except for lappets. Pronotum with irregular dark lateral bands and a wide mesal yellow band. Femora yellow with narrow black apical band. Wing membrane and most veins bown: $R$ vein dark brown, $C$ Pale. Male and female description: see Stark 1988

Nymph: unknown

Material: P.te Quinama, Villa Somoza, 29 Jul 1967, O. S. Flint (USNM)

Anacroneuria planicollis, Klapálek 1923

Anacroneuria dampfi Jewett 1958.

Anacroneuria chiapasa Jewett 1958.

Adult habitus: Head pattern usually with brown ocellar spot, shading to diffuse

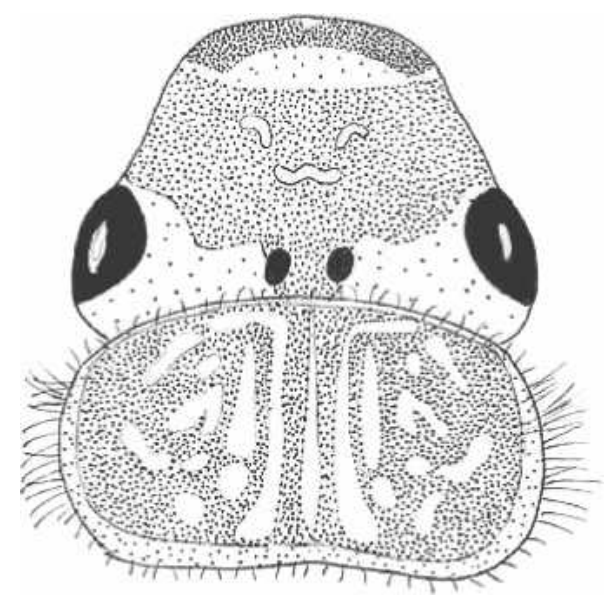

FIG. 7. Head and pronotum of A. talamanca nymph. 


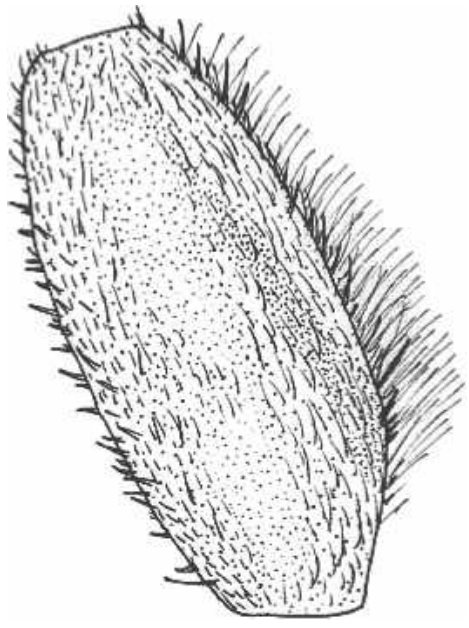

FIG. 8. Femur of $A$. talamanca nymph.

brown forward of ocelli; lappets brown. Medial pronotal stripe brown, bordered by yellow; lateral brown stripes interrupted by scattered pale areas on disc and along margins. Wing membrane transparent, veins brown except $\mathrm{C}$ and Sc pale.

Male and female description: see Stark 1988

Nymph: unknown

Material: Nueva Segovia, Dipilto, Dec. 1986, J. M. Maes (USNM).

\section{Anacroneuria lineata (Navas)}

\section{Neoperla lineata Navas 1924}

Adult habitus: Head with dark pattern over ocelli reaching M-line. Median pronotal stripe brown, bordered by yellow. Margins dark. Wing membrane transparent with veins brown.

Male and female description: see Stark 1988

Nymph: unknown

Material: Chontales, 15-17 IX 2001, J. M. Maes MCCI).

\section{Anacroneuria divisa (Navas)}

\section{Forquilla divisa Navas 1924}

Adult habitus: Head with dark pattern over ocelli onto clypaeus, interrupted by pale M-line. Pronotum with medial stripe, anterior and posterior margins brown.
Wing membrane brown, veins $\mathrm{C}, \mathrm{Sc}$ and $\mathrm{R}$ pale, other veins brown.

Male and female description: see Stark 1988 Nymph: unknown

Material: Cerro Kilambé, 12 VIII 1997, J. M. Maes \& F. Hernandez (MCCI).

\section{Anacroneuria litura (Pictet)}

\section{Perla (Perla) litura, Pictet 1841}

Adult habitus: Head with dark pattern between ocelli and in the frontoclypaeus. Pronotum brown with pale medial stripe. Wings brown.

Male description: see Zwick 1971.

Nymph: unknown

Material: P.te Quinama, Villa Somoza; Esteli, Ducuali. (USNM)

\section{DISCUSSION}

Although it is perhaps premature to produce a preliminary list of Nicaraguan Plecoptera, the known material nonetheless enables construction of a key that has some useful applications. For example, recent studies have indicated that these insects can be used to monitor biological quality of running water habitats and thereby identify alteration of environment (Paaby et al. 1988; Fenoglio et al. 2002, 2004). Thus, to realize this application, neotropical areas will require Plecoptera distribution studies and accompanying keys.

Moreover, during the past decades increasing human population and the overexploitation of the Nicaraguan Pacific slope has caused a rapid decline of water resources in this country. Large rivers and lakes become polluted, mainly through organic contamination. More recently, after the Hurricane Mitch in 1998, there was increased human colonization of the Atlantic region as well. For these reasons, deforestation and water quality alteration actually menace many Anacroneuria habitats in Nicaragua. A more thorough knowledge of the present Plecopterofauna could prove very useful in evaluating biodiversity as well as running water habitat in this tropical country. 
Acknowledgments-I greatly thank Bill Stark for continuous helping and useful comments on different phases of this manuscript. I am also indebted with J. M. Maes for the generous loan of specimens. I also thank T. Bo, R. Fochetti, M. Tierno de Figueroa and P. Zwick for useful suggestions and bibliographic help.

\section{REFERENCES}

Fenoglio, S. 2003. Feeding habits of Anacroneuria nymphs (Plecoptera Perlidae). Boll. Soc. Entom. It. 135: 15-17.

Fenoglio, S., and A. Morisi. 2001a. Anacroneuria starki, a new species from Nicaragua (Plecoptera, Perlidae). Aquat. Insects 23: 311-314

Fenoglio, S. and A Morisi. 2001b. Anacroneuria talamanca, nueva especie para la fauna de Nicaragua (Plecoptera, Perlidae). Rev. Nica. Ent. 55: 5-9.

Fenoglio, S., Badino, G. and F. Bona. 2002. Benthic macroinvertebrate communities as indicators of river environment quality: an experience in Nicaragua. Rev. Biol. Trop. 50: 1125-1131.

Fenoglio, S. and E. Rościszewska. 2003. Characterization of the egg capsules of Anacroneuria starki and A. talamanca (Plecoptera: Perlidae), with a suggestion about stoneflies distribution in tropics. Folia Biol. (Krakow) 51: 159-164.

Fenoglio, S. and M. Tierno de Figueroa. 2003. Observations on the adult feeding of some Neoperla and Anacroneuria species (Plecoptera, Perlidae). Afr. Ent. 11: 138-139.

Fenoglio, S., Bo, T. and Cucco M. 2004. Small-scale macroinvertebrate distribution in a Neotropical Rainforest Strema. Caribb. J. Science 40: 253-257.

Froehlich, C. G. 1981. Plecoptera. In Aquatic Biota of Tropical South America. Part 1. Arthropoda eds. S. H. Hurlbert, G. Rodríguez and N. D. Dos Santos, 8687. San Diego: San Diego State University Press.
Hynes, H. B. N. 1976. Biology of Plecoptera. Ann. Rev. Ent. 21: 135-153.

Illies, J. 1965. Phylogeny and zoogeography of the Plecoptera. Ann. Rev. Ent. 10: 117-140.

Jewett, S. G. 1958. Stoneflies of the genus Anacroneuria from Mexico and Central America (Plecoptera). Am. Mid. Nat. 60: 159-175.

Maes, M. 1988. Catálogo de los Ephemeroptera y Plecoptera de Nicaragua. Rev. Nica. Ent. 2: 49-50.

Marshall, C. J. and J. K. Liebherr. 2000. Cladistic biogeography of the Mexican transition zone. J. Biogeography 27: 203-216.

Paaby, P., A. Ramirez and C. M. Pringle. 1998. The benthic macroinvertebrate community in Caribbean Costa Rica streams and the effect of two sampling methods. Rev. Biol. Trop. 46: 185-199.

Stark, B. P. 1994. Anacroneuria of Trinidad and Tobago (Plecoptera: Perlidae). Aquat. Insects 16: 171-176.

Stark, B. P. 1995. New species and records of Anacroneuria (Klapálek) from Venezuela (Insecta, Plecoptera, Perlidae). Spixiana 18: 211-249.

Stark, B. P. 1998. The Anacroneuria of Costa Rica and Panama (Insecta: Plecoptera: Perlidae). Proc. Biol. Soc. Wash. 11: 551-603.

Stark, B. P. and A. R. Gaufin. 1976. The nearctic genera of Perlidae (Plecoptera). Misc. Publ. Ent. Soc. Am. 10: $1-80$.

Stark, B. P., M. del C. Zúñiga, A. M. Rojas and M. L. Baena. 1999. Colombian Anacroneuria (Klapálek): description of new and old species (Insecta, Plecoptera, Perlidae). Spixiana 22: 13-46.

Stark, B. P. and B. C. Kondratieff. 2004. Anacroneuria from Mexico and upper Mesoamerica (Plecoptera: Perlidae). Mem. West. N. Am. Nat. 2: 1-64.

Stewart, K. W. and B. P. Stark. 1993. Nymphs of North American stonefly genera (Plecoptera). Denton, Texas, University of North Texas Press.

Zwick, P. 1971. Die Plecopteren Pictets and Burmeisters, mit angaben über weitere Arten. Rev. Suisse Zool. 78: 1123-1194.

Zwick, P. 2000. Phylogenetic system and zoogeography of the Plecoptera. Ann. Rev. Ent. 45: 709-745. 